\title{
ARTIKEL
}

\section{Politiële analyse van eerzaken in de rechtszaal*}

\author{
Janine Janssen \& Jeroen ten Voorde
}

\section{Inleiding}

$\mathrm{Al}$ eerder schreven wij in dit en andere tijdschriften over eergerelateerd geweld en strafvorderlijk beleid. ${ }^{1}$ In dat verband besteedden wij aandacht aan de als de 'methode LEC EGG' bekende standaard voor de politiële behandeling voor eerzaken. Op basis van deze werkwijze, die is genoemd naar het Landelijk Expertise Centrum Eer Gerelateerd Geweld (LEC EGG) van de Nederlandse politie, worden zaken waarin geweld dreigt of speelt naar aanleiding van een eermotief geanalyseerd. Deze analyses spelen een rol in de opsporing van geweld uit naam van eer. ${ }^{2}$ Zij helpen namelijk bij het inzichtelijk maken van relevante zoekvragen en het inschatten van eventuele risico's. Maar wat gebeurt er met deze politiële analyses in de rechtszaal? We gingen het na.

\section{De methode LEC EGG}

Waaruit bestaat dan die methode LEC EGG? ${ }^{3} \mathrm{Zij}$ is in feite een 'drietrapsraket'. Bij de eerste stap dienen politieambtenaren alert te zijn op de aanwezigheid van 'rode vlaggen'. Met 'rode vlaggen' worden aspecten van een zaak bedoeld die eventueel duiden op de aanwezigheid van een eermotief. Het kan dan onder andere gaan om aspecten van een zaak die wijzen op een conflict naar aanleiding van een eerschending, zoals uitingen van of dreigen met geweld, beledigingen, roddel en smaad. Daarnaast zijn er rode vlaggen die kunnen duiden op vormen van eerherstel. Het gaat in dit geval niet alleen om alle denkbare vormen van geweld, maar ook om vermissingen of ontvoeringen. Tot slot zijn er vlaggen die te maken heb-

* Dr. Janine Janssen is lector Veiligheid in afhankelijkheidsrelaties aan de Avans Hogeschool in Den Bosch en hoofd onderzoek van het Landelijk Expertise Centrum Eer Gerelateerd Geweld van de Nationale Politie in Den Haag. Samen met Sigrid van Wingerden is zij voorzitter van de redactie van PROCES. Prof. mr. Jeroen ten Voorde is werkzaam aan de Universiteit Leiden en de Rijksuniversiteit Groningen en is rechter-plaatsvervanger in de rechtbank Noord-Holland. Hij is tevens redactielid van PROCES.

1 J. Janssen \& J.M. ten Voorde, 'De strafrechtelijke aanpak van eergerelateerd geweld nader beschouwd', PROCES 2011/2, p. 87-98; J. Janssen \& J.M. ten Voorde, Eergerelateerd geweld en strafvorderlijk beleid: een analyse van de Aanwijzing huiselijk geweld en eergerelateerd geweld, Trema 2010, p. 300-305.

2 Eer is een complex begrip en eergerelateerd geweld een complex fenomeen. Zie daarover o.a. R. Emers, Eer en eerwraak: definitie en analyse, Amsterdam: Bulaaq 2007.

3 Zie voor een beschrijving het in het politieonderwijs en in de basiscursus van de SSR gebruikte leerboek: J. Janssen, Je eer of je leven? Een verkenning van eerzaken voor politieambtenaren en andere professionals, Den Haag: Stapel \& De Koning 2008a. 
ben met achtergronden en gedrag van betrokkenen. Worden er woorden gebruikt die naar eer verwijzen? In hoeverre beschikken individuen over ruimte om eigen keuzes te maken zonder blootgesteld te worden aan heftige vormen van groepsdruk? Al deze vlaggen zijn uitgewerkt in een elektronische zoekslag waarmee dagelijks in alle eenheden politiële informatiesystemen kunnen worden doorgenomen.

De casuïstiek die met behulp van die zoekslag in beeld komt, wordt vervolgens doorgenomen. De ervaring leert dat na een eerste beschouwing veel zaken afvallen. Dat betekent uiteraard niet dat ze geen politiële aandacht behoeven; waar het hier echter om gaat is dat er op dat moment geen aanknopingspunten lijken te zijn waaruit een redelijk vermoeden van het bestaan van een eermotief blijkt. ${ }^{4} \mathrm{Bij}$ de zaken die alsnog overblijven, dient een checklist te worden ingevuld. Dat is de tweede stap. De checklist is géén blauwdruk voor de aanpak van eerzaken. Het is een kwalitatief instrument waarmee informatie wordt verzameld. Daarnaast zijn er ook concrete handreikingen opgenomen die gericht zijn op de uitvoering van het politiewerk. De checklist is opgebouwd uit een aantal blokken met vragen en tips met betrekking tot: de melding; de aard van het probleem; relevante vragen met betrekking tot personalia; relevante vragen met betrekking tot sociale en economische achtergronden; relevante vragen met betrekking tot ervaringen met geweld; het maken van een plan van aanpak; het horen van betrokkenen en het gebruik van tolken; het vastleggen en doorgeven van informatie; de inzet van deskundigen en bemiddeling door de politie. De met behulp van deze lijst verzamelde informatie vormt het fundament onder de analyse en daarmee de aanpak van een zaak waar eer een rol in lijkt te spelen.

De derde stap betreft het inroepen van de hulp van een extern deskundige, bijvoorbeeld een psychiater of een antropoloog. Dat gebeurt alleen in complexe zaken, waarbij specialistische verdieping in het motief van het (dreigende) geweld belangrijke aanknopingspunten zou kunnen bieden in het proces van waarheidsvinding. Als een zaak verder helder lijkt, wordt deze behandeld zonder tussenkomst van een externe deskundige. Inschakeling van een deskundige gebeurt altijd via het LEC EGG. De via de checklist verkregen gegevens en achtergronden zijn voor dergelijke deskundigen essentieel om zich een beeld van een bepaalde situatie te kunnen vormen. ${ }^{5}$ In 2013 werd in 9\% van de zaken die bij het LEC EGG onder de aandacht kwamen, gebruikgemaakt van een externe deskundige. Doorgaans leveren deze deskundigen een schriftelijk advies. Een enkele keer komt ook een kort telefonisch advies voor. ${ }^{6}$

4 In J. Janssen, Instroom en vroegherkenning van mogelijke eerzaken bij de politie: Een onderzoek naar casuïstiek uit 2006, Den Haag: Ministerie van Justitie, Ministerie van Binnenlandse Zaken en Koninkrijksrelaties, LEC EGG 2008b, wordt beschreven hoe in de praktijk met de rode vlaggen en de query wordt gewerkt. Het rapport is als pdf-bestand verkrijgbaar op www. leceergerelateerdgeweld.nl.

5 Zie Janssen 2008a en 2008b.

6 LEC EGG, Terugblik op 2013: Jaarverslag van het Landelijk Expertise Centrum Eer Gerelateerd Geweld, Den Haag: LEC EGG 2014. 


\section{De opsporing}

De laatste jaren is bij de politie veel aandacht besteed aan de kwaliteit van de opsporing. Het voorkomen van de zo gevreesde tunnelvisie ${ }^{7}$ is inmiddels een kleine tien jaar een belangrijk thema bij de politie. ${ }^{8}$ Naar aanleiding van de Schiedammer Parkmoord werd de commissie-Posthumus in het leven geroepen, die in 2005 een kritisch rapport uitbracht met aanbevelingen ten aanzien van opsporing en vervolging. ${ }^{9}$ Korte tijd later werd het 'Programma Versterking Opsporing en Vervolging' (PVOV) ingesteld, dat in 2009 beëindigd is. ${ }^{10}$ Dit programma beoogde met behulp van een pakket maatregelen waarheidsvinding betrouwbaarder te helpen maken. Die maatregelen hebben veel invloed gehad op de praktijk van het recherchewerk.

Behalve organisatorische consequenties heeft het programma ook gevolgen gehad voor het bij de opsporing te hanteren instrumentarium. Een goed voorbeeld is de aandacht voor tegenspraak en 'review', waarmee wordt bedoeld het verkennen van alternatieve scenario's in het opsporingsonderzoek om tunnelvisie te voorkomen. In de wereld van het opsporingsonderzoek vallen tegenwoordig geregeld de termen hypothesen en scenario's. Hypothesen gaan over de vraag wat er gebeurd kan zijn. Een hypothese is dus geen waarheid of een feit, maar een veronderstelling die bewezen - geverifieerd - of verworpen - gefalsifieerd - moet worden. Door hypothesen te formuleren ontstaat een overzicht van de mogelijke toedracht en dus zoekrichtingen. De ene hypothese zal realistischer zijn dan de andere. Door hypothesen te plaatsen in volgorde van waarschijnlijkheid wordt bepaald welke vragen in een onderzoek het meest relevant zijn en dus als eerste gesteld moeten worden en moeten worden beantwoord. Een scenario is een uitwerking van een hypothese. Scenario's gaan over de vraag hoe een voorval uit een hypothese gebeurd zou kunnen zijn. ${ }^{11}$

Het doel van de analyse die bij de politie tot stand wordt gebracht op basis van de methode LEC EGG, is om nader licht op het motief van de betrokkenen te werpen en tot een inschatting van risico's te komen om zo adequaat mogelijk de veiligheid van slachtoffers te kunnen waarborgen. Het gaat hier dus niet direct om bewijsvoering, maar om het richting geven aan het zoekproces van de politie, dat uiteraard wel kan bijdragen aan de bewijsvoering. Deze analyse met behulp van de methode LEC EGG moet er met andere woorden simpelweg toe bijdragen dat in de opsporing hypothesen en scenario's kunnen worden geformuleerd op grond

7 Zie daarover M. Bollen, Tunnelvisie als bedrijfsrisico, Deventer: Kluwer 2006.

8 M. van Kuijk, 'Tunnelvisie', in: N. Kop, R. van der Wal \& G. Snel (red.), Opsporing belicht: over strategieën in de opsporingspraktijk, Apeldoorn: Politieacademie 2011, p. 297-311.

9 Commissie Posthumus, Evaluatieonderzoek in de Schiedammer parkmoord: rapportage in opdracht van het College van procureurs-generaal, Amsterdam 2005.

10 Openbaar Ministerie, Politie \& NFI, Versterking opsporing en vervolging naar aanleiding van het evaluatierapport van de Schiedammer Parkmoord, 4 november 2005. Zie ook Kamerstukken II 2005/06, 30300 VI, 32.

11 K. Snijders, 'Werken met hypothesen en scenario's', in: N. Kop, R. van der Wal \& G. Snel (red.), Opsporing belicht: over strategieën in de opsporingspraktijk, Apeldoorn: Politieacademie 2011, p. 277-284. 
waarvan relevante vragen kunnen worden gesteld. Stel dat er een lichaam van een jonge vrouw wordt gevonden, dan zijn relevante vragen of het hier om een natuurlijk overlijden, een ongeluk, een zelfmoord of een moord gaat.

\section{In de rechtszaal}

In het vorige decennium stonden fenomenen als eergerelateerd geweld in het middelpunt van de belangstelling. Veel aandacht ging uit naar de omschrijving van de problematiek en het opstellen van plannen om de problematiek aan te pakken, terwijl vanuit de samenleving en de politiek geroepen werd om een ferme aanpak, mede ingegeven door een toenemende ongerustheid over de integratie van allochtonen in de Nederlandse samenleving. Verschillende instanties hebben het nodige werk verzet om de aanpak van eergerelateerd geweld gestalte te geven. In de evaluatie van de strafrechtelijke aanpak van eergerelateerd geweld uit 2012 wordt aangegeven dat door de politie en andere (hulpverlenings)instanties weliswaar veel werk is verzet, maar dat er geen zicht is op het resultaat van de inspanningen van politie en Openbaar Ministerie op het terrein van opsporing en vervolging. ${ }^{12}$ De rechter wordt in dit verband zelfs niet genoemd. Dat is opmerkelijk, omdat de Aanwijzing Huiselijk geweld en eergerelateerd geweld opmerkt dat ernstige vormen van eergerelateerd geweld worden vervolgd. Uit eerder jurisprudentieonderzoek is gebleken dat eergerelateerde feiten wel worden berecht en in sommige gevallen de eergerelateerde achtergrond wordt betrokken bij de vragen van artikelen 348-350 van het Wetboek van Strafvordering (Sv). ${ }^{13}$ Dat onderzoek is inmiddels al weer wat ouder en werd voornamelijk uitgevoerd voordat het LEC EGG in het leven werd geroepen. De vraag is of en op welke wijze de rechter rekenschap geeft van de (extra) inspanningen die de politie moet verrichten in het kader van zaken met een mogelijk eergerelateerd karakter.

Die vraag spitsten we toe op de rapportages van het LEC EGG. Worden die in de einduitspraak van de rechter gebruikt en zo ja, op welke wijze? Het gaat in dit onderzoek niet om een analyse van de rapporten zelf, de kwaliteit ervan, de inhoud en de wijze van totstandkoming, maar om de manier waarop de rechter in zijn uitspraak zichtbaar maakt of en op welke wijze gebruik wordt gemaakt van deze rapportages. ${ }^{14} \mathrm{Om}$ deze vraag te beantwoorden voerden we een rechtspraakonderzoek uit met behulp van de zoekmachine op rechtspraak.nl. ${ }^{15}$ Onder strafzaken is gezocht op 'landelijk expertise centrum eergerelateerd geweld', 'landelijk expertisecentrum eergerelateerd geweld, 'LEC EGG' en 'LEC-EGG'. Dat onderzoek leverde in totaal acht einduitspraken op. Dat lijkt wellicht weinig, maar opgemerkt moet worden dat de strafrechtspleging een afvalrace is: slechts een klein

12 L. Loef \& M. van Aalst, Evaluatie strafrechtelijke aanpak eergerelateerd geweld, Amsterdam/Den Haag: DSP-Groep/WODC 2012.

13 Zie bijv. M. Siesling, Multiculturaliteit en verdediging in strafzaken (diss. Utrecht), Den Haag: Boom Juridische uitgevers 2006; M. Siesling \& J. ten Voorde, Verdediging in culturele strafzaken, Den Haag: Sdu 2009.

14 Zie daarvoor Loef \& Van Aalst 2012.

15 Voor het laatst geraadpleegd op 26 augustus 2015. 
deel van de ter kennis van de politie gekomen misdrijven leidt daadwerkelijk tot berechting door de strafrechter. ${ }^{16}$ Dat is voor eerzaken niet anders. Daarnaast is nog van belang op te merken dat het doel van het beleid inzake de aanpak van eergerelateerd geweld is het voorkómen van geweld door in een zo vroeg mogelijk stadium in te grijpen (al dan niet door middel van bemiddeling) in een mogelijk ontluikend eerconflict. ${ }^{17}$ De methode LEC EGG is er juist op gericht om signalen van een eerconflict te onderkennen voordat sprake is van geweld. Veel zaken die met behulp van de methode LEC EGG aan het licht komen, betreffen beledigingen, die, al dan niet strafbaar, lang niet altijd tot een berechting leiden (al was het maar omdat er geen klacht wordt ingediend, nodig voor het kunnen vervolgen van belediging (art. 269 Wetboek van Strafrecht)). Een belediging kan wel aanleiding geven te onderzoeken wat er aan de hand is, om vervolgens, indien er sprake is van een mogelijk eerconflict, te komen tot een oplossing (anders dan strafrechtelijke vervolging) voordat het conflict in geweld ontaardt.

Terug naar de rechtspraak. De eerste keer dat in een einduitspraak naar het LEC EGG wordt verwezen, is in 2009. De meest recente einduitspraak dateert van 2014. De overige uitspraken zijn van 2011, 2012 en 2013. De analyse beperkt zich tot deze einduitspraken. Uitspraken waarin naar het LEC EGG is verwezen maar die niet op rechtspraak.nl zijn gepubliceerd, blijven, voor zover deze aanwezig zijn, buiten beschouwing. Ook uitspraken over zaken waarin wel is gerapporteerd door het LEC EGG, maar die uiteindelijk niet door de rechter zijn gebruikt, worden evenmin besproken. Overigens weten we op basis van ons rechtspraakonderzoek dat rapportages van het LEC EGG soms niet worden vermeld in het vonnis of arrest, terwijl ze wel deel uitmaken van het dossier. ${ }^{18}$ Wat de reden daarvan in elk van deze gevallen is, kon niet worden achterhaald. In zijn algemeenheid geldt dat de rechter vrij is in de selectie en waardering van het bewijsmateriaal. ${ }^{19}$ Het is mogelijk dat de rapportage van het LEC EGG niet nodig was voor het bewijs (of voor de beantwoording van de overige vragen van art. $350 \mathrm{~Sv}$ ). Soms wordt wel naar de rapportage van het LEC EGG verwezen, maar daarvan vervolgens geen gebruik gemaakt. In die gevallen bleven de redenen daarvoor onvermeld. ${ }^{20}$ De uitspraken doen vermoeden dat voldoende bewijsmiddelen voorhanden waren om tot een bewezenverklaring van de aan de verdachte ten laste gelegde feiten te komen zonder dat de rapportage daarvoor nodig was. De vraag is of dit utiliteitsargument de lading voldoende dekt. Er zijn ook andere verklaringen te geven.

16 Zie o.a. N.E. de Heer-de Lange \& S.N. Kalidien (red.), Criminaliteit en rechtshandhaving, Den Haag: Sdu 2014, i.h.b. hoofdstuk 8.

17 Zie Janssen \& Ten Voorde 2011.

18 Zie Rb. Groningen 11 oktober 2010, ECLI:NL:RBGRO:2010:BO0132 en Hof Leeuwarden 4 mei 2011, ECLI:NL:GHLEE:2011:BQ3496. In het vonnis van de rechtbank wordt niet naar een rapportage van het LEC EGG verwezen, in het arrest van het hof wordt echter melding gemaakt van een rapportage van het LEC EGG d.d. 25 mei 2010, vastgesteld voor de eerste zittingsdatum van de rechtbank en dus - mogen we aannemen - onderdeel van het dossier.

19 G.J.M. Corstens, Het Nederlands strafprocesrecht (bewerkt door M.J. Borgers), Deventer: Kluwer 2014, p. 848-850. Daarmee is natuurlijk niet gezegd dat elke selectie en waardering door de beugel kan. De Hoge Raad pleegt de bewijsconstructie weldegelijk te controleren, zij het beperkt.

20 Hof Leeuwarden 4 mei 2011, ECLI:NL:GHLEE:2011:BQ3496; Hof Arnhem-Leeuwarden 28 februari 2013, ECLI:NL:GHARL:2013:BZ2740. 
Wellicht, maar nu begeven we ons ten aanzien van de rapportage van het LEC EGG op glad ijs, werd de rapportage in de zaken waarin zij niet werd gebruikt, niet beschouwd als bewijsmiddel, maar enkel als informatie die verder niet voor het bewijs kan worden gebruikt. In de zaak die leidde tot een arrest van het Hof Arnhem wordt in het arrest melding gemaakt van een in het politieproces-verbaal opgenomen 'Analyse (mogelijk) eergerelateerd geweld'. Wie deze analyse heeft verricht en naar aanleiding waarvan het proces-verbaal is opgemaakt, blijkt niet uit het arrest. Niet gezegd is dat hier sprake is van een analyse van het LEC EGG. Het hof gebruikt de analyse in ieder geval niet voor het bewijs, omdat volgens het hof 'niet blijkt dat degenen die deze analyse hebben uitgevoerd zijn ingeschreven in het openbaar register van gerechtelijk deskundigen als bedoeld in art. $51 \mathrm{k} \mathrm{Sv}$ terwijl evenmin voldoende blijkt op grond van welke opleiding en ervaring zij in staat geacht mogen worden tot conclusies te kunnen komen zoals in deze analyse verwoord'. ${ }^{21}$

Het arrest roept de vraag op of een rapportage van het LEC EGG wel als deskundigenverslag in de zin van artikel $511 \mathrm{~Sv}$ moet worden beschouwd, en de opsteller van het verslag als deskundige in de zin van artikel 51i Sv. In de Aanwijzing Technisch onderzoek/deskundigenonderzoek wordt dit onderscheid uitgewerkt. ${ }^{22}$ Of van een van beide onderzoeken sprake is, is afhankelijk van de fase van het opsporingsonderzoek en het onderzoeksgebied. De fase van het opsporingsonderzoek bestaat uit de voorfase van het opsporingsonderzoek en de analyse/interpretatiefase. Onderzoek dat in de voorfase plaatsvindt, is geen deskundigenonderzoek. Onderzoek dat in de analyse/interpretatiefase plaatsvindt, kan op grond van de Aanwijzing Technisch onderzoek/deskundigenonderzoek zijn, maar dat hoeft niet. Gestandaardiseerd en reproduceerbaar onderzoek, zoals het vaststellen van alcohol in bloed of urine of toetsing van vuurwerk, is geen deskundigenonderzoek. Bijlage 2 van de aanwijzing geeft een limitatieve opsomming van gestandaardiseerd en reproduceerbaar onderzoek. Is van dergelijk onderzoek geen sprake, dan moet worden bepaald of het onderzoek behoort tot een van de onderzoeksgebieden die limitatief zijn opgesomd in bijlage 3 van de Aanwijzing Technisch onderzoek/deskundigenonderzoek. Als dat het geval is, is er ook geen sprake van deskundigenonderzoek, tenzij het onderzoek wordt uitbesteed aan een derde. In dat geval is er wel sprake van een deskundigenonderzoek. ${ }^{23}$ In dat geval gelden de wettelijke vereisten van de artikelen 51i e.v. Sv en de artikelen 150 e.v. Sv. Daaruit volgt op grond van rechtspraak van de Hoge Raad echter niet dat wanneer een deskundigenrapport niet conform de wettelijke vereisten tot stand is gekomen, het niet voor het bewijs mag worden gebruikt. ${ }^{24}$

Wat leert het voorgaande ons ten aanzien van de rapportage van het LEC EGG? De rapportage wordt door de politie primair gezien ter ondersteuning van het

21 Hof Arnhem 22 april 2011, ECLI:NL:GHARN:2011:BQ3264.

22 Aanwijzing (2013A011) van 7 mei 2013, Stcrt. 2013, nr. 13962.

23 Dan moet een geregistreerd deskundige worden benoemd. Alleen een rechter mag een niet-geregistreerd deskundige benoemen (art. 51k lid $2 \mathrm{~Sv}$ ). Zie voor de eisen waaraan een persoon moet voldoen, wil hij als deskundige in het register kunnen worden opgenomen, art. 12 lid 2 van het Besluit van 18 juli 2009, Stb. 2009, 330 (Besluit register deskundige in strafzaken). 
onderzoeksproces en het identificeren van risico's in verband met de zorg voor de veiligheid van slachtoffers. De rapportage is dus niet geschreven om te dienen als bewijsmiddel in een strafzaak. De rechter lijkt dat anders te zien; hij neemt kennis van de rapportage als onderdeel van het dossier en neemt de rapportage mee in de selectie en waardering van het bewijsmateriaal. Voor de rechter is een rapportage bewijsmateriaal, wat de politie daar ook van moge vinden. Vanuit deze optiek valt de wijze waarop de rechter met de rapportage omgaat, namelijk als onderdeel van het dossier zoals elk ander onderdeel, wel te begrijpen. Hij wikt en weegt en vergelijkt de rapportage met de rest van de informatie die in het dossier zit. Het voorgaande biedt een verklaring voor het arrest van het Hof Arnhem. Dat probeerde de zich in het dossier bevindende rapportage te begrijpen en de betrouwbaarheid te toetsen op grond van de wettelijke regeling over de deskundige. Op grond van de aanwijzing moet echter worden aangenomen dat het onderzoek door het LEC EGG (en de op basis daarvan tot stand gekomen rapportage) deskundigenonderzoek noch technisch onderzoek betreft, maar moet worden beschouwd als onderzoek dat de politie uitvoert in het kader van de strafrechtelijke handhaving van de rechtsorde.

Een andere verklaring voor het niet gebruiken van de rapportage van het LEC EGG kan zijn dat de inhoudelijke waarde ervan wordt gerelativeerd. In een moordzaak baseerde de officier van justitie het motief voor de aan verdachte ten laste gelegde moord onder andere op een rapportage van het LEC EGG. Verdachte zou het slachtoffer vanwege overspel van het leven hebben beroofd. In de rapportage van het LEC EGG, we citeren hierna uit het vonnis, wordt aangegeven tot welke reactie overspel leidt in 'de Turkse cultuur' en hoe het leidt tot de omstandigheid dat verdachte en zijn vrouw de familie van het slachtoffer niet zijn komen condoleren: 'In de Turkse cultuur is dat feitelijk niets minder dan een schuldbekentenis.' Het LEC EGG geeft volgens de rechtbank ook een interpretatie van de OVC-gesprekken die zich in het dossier bevinden. Daaruit leidt het LEC EGG af dat het slachtoffer de vrouw van verdachte oneervol zou hebben bejegend. De vrouw zou dit hebben gezegd tegen verdachte, waardoor deze de eer moest zuiveren. Als de vrouw daarover niets zou hebben gezegd, zou verdachte de eer niet hebben hoeven zuiveren, aldus de moeder van verdachte. Een deel van de uitlatingen van de moeder 'lijkt (...)', aldus het LEC EGG, 'niet anders te verklaren dan dat verdachte de dood van het slachtoffer op zijn geweten heeft'. De rechtbank spreekt de verdachte echter vrij van de ten laste gelegde moord en doodslag. Dat verdachte op de hoogte is geweest van de 'affectieve relatie' tussen zijn vrouw en het slachtoffer 'kán' volgens de rechtbank 'een motief opleveren en kán evenzeer een motief voor eerwraak zijn, maar kan in het licht van de vastgestelde feiten [er was in deze zaak geen rechtstreeks bewijs op grond waarvan verdachte als de schutter kon worden aangewezen; JJ en JtV] niet leiden tot een bewezenverklaring van hetgeen aan de verdachte ten laste is gelegd'. ${ }^{25}$ Duidelijk is dat de analyse van het LEC EGG niet zonder meer door de rechtbank wordt overgenomen. Het lijkt erop dat de rechtbank de rapportage wat aan de speculatieve kant vindt en, 
gevoegd bij het overige vrij magere bewijs dat in de richting van verdachtes daderschap zou leiden, de rechtbank spreekt hem vrij.

Minder duidelijk, maar wellicht ook verklaarbaar als wordt aangenomen dat de rapportage wordt gerelativeerd, is de uitspraak van de Rechtbank Groningen van 10 november $2011 .{ }^{26}$ De officier van justitie stelt dat het volgens het LEC EGG aannemelijk is dat verdachte zich aangetast voelde in zijn mannelijke eer. Mede op basis van de rapportage van het LEC EGG acht hij de ten laste gelegde voorbedachte rade bewezen. De rechtbank is echter van oordeel dat niet is komen vast te staan of 'eerwraak' het motief voor de gepleegde feiten is geweest. Veel meer woorden maakt de rechtbank er niet aan vuil, maar de indruk bestaat dat de rechtbank de inhoud van de rapportage van het LEC EGG niet zo overtuigend acht dat het, in combinatie met de overige bewijsmiddelen, duidelijk is geworden met welk motief de verdachte het hem ten laste gelegde heeft gepleegd.

Hoe moeten we deze uitspraken bezien? Hiervoor stelden we al dat de rechter vrij is in de selectie en waardering van bewijsmateriaal. Dat is niet anders ten aanzien van rapportages van het LEC EGG. De rechter beoordeelt een dergelijke rapportage in het licht van het overige bewijsmateriaal en het verhandelde ter zitting. In zoverre valt weinig op te merken over het gebruik van rapportages van het LEC EGG. Niet kan worden gezegd dat de rechter zichzelf een zekere deskundigheid op het terrein van eer en eergerelateerd geweld aanmeet, iets wat wel in oudere rechtspraak is gesignaleerd. ${ }^{27}$ De rechter maakt een afweging en komt in de beoordeling tot een andere waardering van de feiten en omstandigheden.

De rapportages van het LEC EGG worden soms verschillend gebruikt. In de zaak die leidde tot ECLI:NL:RBMID:2012:BV7312 had het LEC EGG gerapporteerd dat de zaak eergerelateerd is, 'waarbij de kans op eergerelateerd geweld groot is'. Verdachte en zijn vrouw waren uit elkaar gegaan, maar verdachte kon dat moeilijk verkroppen. Hij was naar haar (en de kinderen) op zoek en de vraag was of hij een ernstig strafbaar feit aan het voorbereiden was. Volgens het LEC EGG was de kans op eergerelateerd geweld dus groot. Deze uitkomst van de analyse door het LEC EGG paste volgens de officier van justitie in het geheel van bewijsmiddelen op basis waarvan verdachtes voorbereidingshandelingen konden worden bewezen. De officier van justitie verwees ook naar de rapportage bij het formuleren van de strafeis. De rechtbank verwijst in haar vonnis wel naar de rapportage en concludeert dat daaruit een 'zeer zorgelijk beeld' naar voren komt, maar dat is 'onvoldoende om daaruit een concrete misdadige intentie van verdachte af te leiden'. De rechtbank verwijst bij het bepalen van de straf niet naar de rapportage van het LEC EGG.

In hoger beroep wordt door de advocaat-generaal opnieuw naar het rapport verwezen, waarin - zo blijkt uit het arrest van het hof - onder andere verschillende meldingen waren opgenomen over verdachte (onder andere dat tegen hem een rechtszaak in Turkije ter zake van mishandeling zou lopen en dat hij zich zou hebben opgehouden in de buurt van de school van de kinderen van de zus van zijn exvrouw). Ook heeft het LEC EGG verdachtes ex-vrouw en kinderen geadviseerd 
naar een nieuw geheim te houden adres te verhuizen. Dat advies werd echter niet opgevolgd. De meldingen konden door het Openbaar Ministerie niet worden geverifieerd (een rechtshulpverzoek aan Turkije had geen antwoord opgeleverd), zodat het hof 'niet op grond van objectieve bescheiden [kan] vaststellen of en op welke wijze en met welk motief dit feit [de mishandeling] is gepleegd, zodat het hof evenmin kan beoordelen of dit feit in een nauw en direct verband staat met de ten laste gelegde handelingen'. Uit het feit dat de vrouw het advies van het LEC EGG niet heeft opgevolgd, 'blijkt' volgens het hof 'nog niet direct dat het gezin iets te vrezen had van verdachte'. ${ }^{28}$ Verdachte wordt ook door het hof vrijgesproken van strafbare voorbereidingshandelingen.

Uit deze zaak blijkt dat de waarde van een rapportage van het LEC EGG per procesfase kan verschillen. Het is heel wel denkbaar dat de meldingen die in de rapportage zijn opgenomen, aanleiding kunnen zijn om de bescherming van het gezin op te voeren en het gesprek tussen de betrokkenen aan te gaan, in de hoop dat het conflict de-escaleert. Dergelijke informatie kan voor een rechter weinig meer dan geruchten zijn op basis waarvan geen beslissing kan worden gebaseerd. De Rechtbank Dordrecht maakte voor het bewijs van moord wel gebruik van de rapportage van het LEC EGG. De raadsman van verdachte stelt dat uit de rapportage zou blijken dat van 'eerwraak' geen sprake is, omdat verdachte geen overleg heeft gevoerd met anderen. De rechtbank stelt dat de conclusie van het LEC EGG niet eenduidig is, maar dat eergerelateerde motieven naast persoonlijke belangen een rol hebben gespeeld bij de moord op verdachtes moeder en de poging tot moord op verdachtes zus. ${ }^{29}$

\section{Verdere analyse}

De rapportages worden in alle uitspraken waarin daarnaar wordt verwezen, behandeld bij de vraag of het ten laste gelegde feit bewezen kan worden verklaard (de eerste vraag van art. $350 \mathrm{~Sv}$ dus). In één zaak werd door de officier van justitie naar de rapportage van het LEC EGG verwezen bij het bepalen van de strafeis, maar de rechtbank maakt geen gebruik van de rapportage bij het formuleren van de straf. De rapportage wordt door de officier van justitie (of advocaat-generaal) gebruikt bij het bewijzen van de intentie of het motief. Dat kan een rol spelen bij moord (voorbedachte raad), maar ook bij voorbereidingshandelingen (bewijs van de bestemming van de voorwerpen die verdachte volgens de tenlastelegging voorhanden had).

De uitspraken maken niet altijd duidelijk wat precies wordt gerapporteerd. De door het LEC EGG gegeven achtergrondinformatie over eergerelateerd geweld wordt soms in de uitspraak (verkort en zakelijk) weergegeven. De door het LEC EGG gegeven interpretatie van de feiten en omstandigheden hoeft niet eenduidig te zijn, waardoor de rechter een zekere vrijheid heeft in het gebruik van de rapportage. Dat die vrijheid soms erg groot is, terwijl niet kan worden gecontroleerd 
hoe een rechtbank tot het oordeel is gekomen, blijkt uit ECLI:NL:RBMID:2012: BV7312. In dat vonnis wordt slechts melding gemaakt van de conclusie van het LEC EGG, zonder dat duidelijk is waarop die conclusie is gebaseerd. De rechtbank deelt de conclusie niet helemaal, maar maakt niet duidelijk waarom. Dat maakt de lezer nieuwsgierig naar de inhoud van de rapportage en de precieze redenen waarom de conclusies niet worden gedeeld. Het arrest van het hof in deze zaak maakt een en ander wat duidelijker: de conclusies lijken deels te zijn gebaseerd op niet geverifieerde politie-informatie. Het hof maakt duidelijk daar niet veel mee te kunnen en legt om die reden de rapportage van het LEC EGG min of meer naast zich neer.

Het naast zich neerleggen van rapportages van het LEC EGG in de rechtspraak, althans in verschillende van de door ons gevonden uitspraken, roept de vraag op waarom de rapportages niet worden gebruikt. Daarop zijn verschillende antwoorden te formuleren. Vanuit het perspectief van de rechter bezien is het denkbaar dat dergelijke rapportages niets toevoegen aan het bewijs en om die reden ter zijde kunnen worden gelegd. Er zijn verschillende redenen waarom de rapportages volgens de rechter niets toevoegen: de rechter heeft al voldoende informatie om tot een bewezenverklaring te komen en heeft de rapportage niet nodig, of de rechter vindt de inhoud van de rapportage onvoldoende stevig om te kunnen gebruiken voor het bewijs. Dat laatste laat zich verklaren doordat deze rapportages niet voor het bewijs, maar voor de opsporing zijn bedoeld en dan vooral als hulpmiddel bij het formuleren van scenario's. Vanuit het perspectief van de officier van justitie bezien kan hetzelfde worden gezegd voor zover de rapportage voor het bewijs wordt gebruikt. Voor de officier van justitie kan het noemen van de rapportage in het requisitoir het gevolg zijn van de relevantie ervan tijdens het opsporingsonderzoek. Omdat de rapportage bijvoorbeeld hielp bij het begrijpen van wat er is gebeurd of bij het schetsen van scenario's en een bijdrage heeft geleverd in het bepalen van de rol van verdachte, kan dat voor de officier van justitie een reden zijn de rapportage in het requisitoir te noemen, bijvoorbeeld in het kader van medeplegen (al hebben we dat niet kunnen achterhalen in de gevonden uitspraken), maar ook in het kader van voorbedachte raad. De uitspraken geven geen (duidelijk) inzicht in hoeverre de rapportage door de verdediging is gebruikt ten behoeve van het voeren van verweer, bijvoorbeeld een strafmaatverweer. Voor zover door de verdediging is gewezen op de rapportage, is dat vooral in kritische zin. Zowel vanuit het perspectief van de politie als vanuit dat van de rechterlijke macht en de advocatuur is het onbevredigend dat de vraag naar de doorwerking van de rapportages van het LEC EGG in de rechtszaal niet goed kan worden beantwoord. Het hier gepresenteerde verkennende onderzoek maakt in ieder geval wel duidelijk dat de politie en rechters andere verwachtingen hebben ten aanzien van deze rapportages: waar het bij de rechter met name om bewijsvoering gaat, staan bij de politie structurering van het opsporingsproces en het indammen van risico's ten aanzien van de veiligheid van slachtoffers centraal. 